\title{
Transonic Aerodynamic Analysis of Different Forebody Shapes of Aerospace Vehicles
}

\author{
Ana Cristina Avelar, ${ }^{1}$ João Batista Falcão Filho, ${ }^{1}$ Layra Mendonça Silva²
}

Avelar AC (1) https://orcid.org/0000-0002-0333-4570

Falcão Filho JB (C) https: / / orcid.org/0000-0002-5347-6091

Mendonça Silva L (1) https: / / orcid.org/0000-0002-4206-3793
How to cite

\begin{abstract}
Avelar AC; Falcão Filho JB, Mendonça Silva L (2020) Transonic Aerodynamic Analysis of Different Forebody Shapes of Aerospace Vehicles J Aerosp Tecnol Manag, 12: e1520. https://doi.org/10.5028/jatm.v12.1103.
\end{abstract}

\begin{abstract}
One of the most important features of an aerospace vehicle design is its shape, especially the forebody part, since it defines the main characteristics of the vehicle aerodynamic. In this context, the present work has the purpose of investigating the transonic aerodynamic regime in typical vehicle models, with different frontal geometry configurations, using the experimental techniques pressure sensitive paint (PSP) and Schlieren. The aim is to get more insights about the flow patterns over the selected models, regarding the transonic regime, in terms of qualitative density field evaluation, and the identification of important aerodynamic parameters, such as shock wave positioning and pressure gradients over the model, as well as the influence of the forebody configuration in the flow pattern. The test campaign was carried out in the Pilot Transonic Wind Tunnel of the Institute of Aeronautics and Space (IAE; in Portuguese, Instituto de Aeronáutica e Espaço), varying Mach numbers from subsonic to low supersonic. Five forebody configurations mounted in a cylindrical body having the standard cone-cylinder shape as baseline was considered. A description of the phenomena occurring around and on the models surface for all five models is presented, through analyses of the Schlieren images and PSP results.
\end{abstract}

KEYWORDS: Transonic Aerodynamic Analysis, Aerospace Vehicles, Pressure-sensitive paint, Fore-body, Shapes.

\section{INTRODUCTION}

Of the many human inventions which have radically transformed the world, such as electricity, airplanes, computers, and nuclear weapons, rockets remain as an awe-inspiringly technology, because of their stunningly complex characteristics, as stated by Riper (2004). While other technologies are in a stage of knowledge and development practically operational, there are still many needed advances in rocket technology, due to difficulties faced in its application, regarding especially its mission and safety criteria.

The use of rockets, both in war and in times of peace, have surprisingly advanced with World War II, resulting in the current understanding of the three distinct uses of rockets: long-range "strategic" missiles, short-range "tactical" missiles, and "launch vehicles" to carry payloads into space. During the last decades, refined versions of those rockets have reshaped the world, transformed science, politics, economics, and, above all, warfare (Riper 2004).

Since the space activities have become essential for all countries, Brazil has been striving to maintain continuous advances, through the creation of the Brazilian Space Program (PEB; in Portuguese, Programa Espacial Brasileiro), which includes the

1. Departamento de Ciência e Tecnologia Aeroespacial - Instituto de Aeronáutica e Espaço - Divisão de Aerodinâmica - São José dos Campos/SP - Brazil

2. Departamento de Ciência e Tecnologia Aeroespacial - Instituto Tecnológico de Aeronáutica - São José dos Campos/SP - Brazil.

*Correspondence author: anacristina.avelar@gmail.com

Received: Jan. 23, 2019 | Accepted: Jul. 02, 2019

Section Editor: Juan Pablo Salazar 
research and development of launch vehicle technologies, satellite production, and space exploration. Currently, the Brazilian space area is promoted by the National Policy of Development of Space Activities (PNDAE; in Portuguese, Política Nacional de Desenvolvimento de Atividades Espaciais), which establishes objectives and guidelines for national programs and projects related to space, with emphasis on the National Program of Space Activities (PNAE; in Portuguese, Programa Nacional de Atividades Espaciais) (Da Mata 2013). Most of the space activities in Brazil are conducted by IAE, which belongs to the DCTA (in Portuguese; Departamento de Ciência e Tecnologia Aeroespacial). IAE has been developing national orbital and suborbital launch vehicles since the 1960s.

For this purpose, a family of vehicles called Sonda was created (in Portuguese sonda means probe), and, in the mid1960s, the first Brazilian suborbital vehicle, called Sonda I (or SI), was launched for atmospheric exploration. Figure 1 shows an exploded view of a more advanced vehicle, Sonda III (or SIII), in its conceptual definition. Sonda III is a modern solid fuel sounding rocket, with two stages, although having a relatively simple shape configuration. The vehicle has been developed by IAE since 1970, with the first launch in 1976, to explore sub-orbital space. Its main characteristics are: maximum external diameter of $0.557 \mathrm{~m}$; total length of $6.72 \mathrm{~m}$; total weight of 1,615 kg; payload of $60 \mathrm{~kg}$; apogee of $700 \mathrm{~km}$; and time in microgravity condition of $750 \mathrm{~s}$. Figure 1 highlights typical devices for specific functions, namely: (1) ogive; (2) equipment bay; (3) payload bay; (4) separation ring; (5) coupling cone; (6) igniter; (7) motor case; (8) propellant; (9) nozzle; (10) fin; and (11) fin holder. All the features included in the physical design, together with the determination of operational procedures, form the data set for the vehicle to perform its mission: from its assembly in the launch ramp to the evaluation of its final objective (Palmério 2016).

One of the initial and most important concerns in an aerospace vehicle design is its shape, which will define its aerodynamic characteristics. The simple aerodynamic configurations used in the first rockets evolved into more complex shapes, paying great attention to the aerodynamic behavior of the vehicles. This is especially true concerning the forebody part, where pressure drag and shock wave formation play important roles, being still issues of constant investigation.

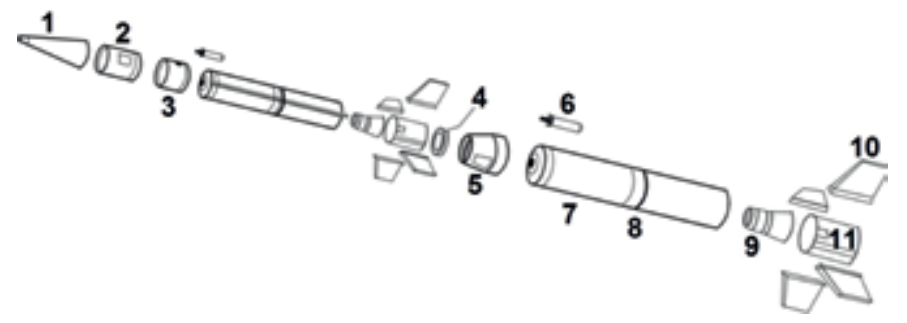

Figure 1. Exploded view of the SIII rocket from IAE, as adapted from Palmério (2016).

A recent research effort, in Brazil, within aerospace field is a project for implementing an academic cooperation network, financially supported by the Brazilian Coordination of Higher Education Personnel (CAPES; in Portuguese, Coordenação de Aperfeiçoamento de Pessoal de Nível Superior). Such project is entitled Validation in Propulsion and Aerodynamics of Rockets. The present work represents part of this effort, providing data for comparison purposes, with further numerical simulations developed by the network project (Silva 2017).

The main purpose of Silva's research (2017) was investigating the transonic aerodynamic regime in typical vehicle models, with different frontal geometry configurations, using experimental and theoretical approaches. Some important questions were investigated, such as: (1) understanding flow behavior in transonic regime, in terms of qualitative density field evaluation over the model, by means of Schlieren images, as well as quantitative surface pressure field measurements on its surface, by means of PSP technique; (2) identification of important aerodynamic parameters, such as drag coefficient, by means of internal balance; (3) determination of shock wave positioning and flow patterns; (4) implementation of simple codes to predict drag; and (5) identification of best frontal configuration, which could result in the lowest drag coefficient. 
One of the most famous aerodynamic shapes for space vehicles is the cone-cylinder, which is widely reported in the literature. Therefore, the cone-cylinder was one of the selected models for the tests, as it could be used to predict typical flow patterns. Figure 2 gives an illustrative idea of how the flow pattern would be like when a cone-cylinder body is submitted to transonic flow regime. The presence of the body accelerates the flow field locally to supersonic conditions, creating four distinct regions. Each one has the following specific main characteristics: (1) undisturbed subsonic flow condition; (2) compressed and accelerated flow region, caused by the presence of the front body; (3) expanded supersonic region starting in the vicinity of the corner; and (4) region adapted to subsonic flow conditions, after a shock wave, to cope with the undisturbed flow conditions downstream. Particularly, the boundaries of the supersonic region can be well-defined by a sonic line at the entrance and a shock wave at the exit. The supersonic region becomes larger as the Mach number of the undisturbed flow increases.

Considering the boundary layer along the model body, it is possible to understand that, close to the tip of the model, it is initially laminar. In a real vehicle, with a larger scale, the transition to turbulent regime obviously occurs very early. For this reason, in the models tested, a transition band was installed at about $10 \%$ of the model length, in order to force the transition to occur somewhere close to where it would in a real flight situation, as recommended by the literature (Pope and Goin 1978). This strategy is mostly used to improve skin friction drag estimation, making necessary some prediction of the boundary layer condition through the model. The models with blunt nose did not have a transition band installed, due to the lack of space for it.

A more difficult problem appears when the flow experiences expansion at the vicinity of the corner - at the beginning of the cylindrical part of the model. Strong favorable pressure gradient promotes flow acceleration of the boundary layer, causing it to re-laminarize. Of course, it is not appropriate to use a transition band in this region, because of its intrusive effects on the formation of shock wave structure.

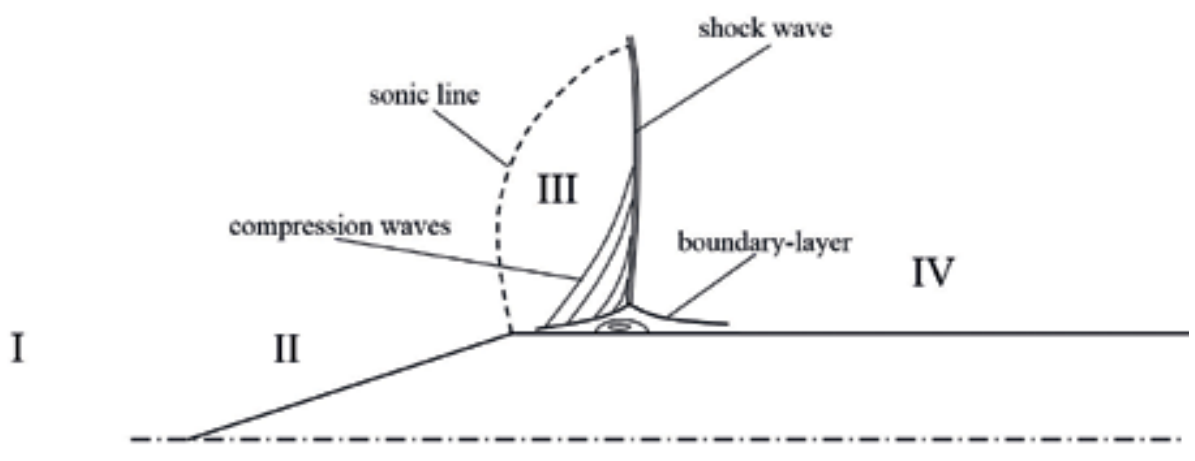

Figure 2. Typical flow pattern scheme of a cone-cylinder model at transonic flow regime. Adapted adapted from Ramaswamy and Rajendra (1978).

The term re-laminarization represents the way the flow goes from turbulent back to laminar regime. This is an old issue, as Geoffrey Ingram Taylor, in 1929, could observe it in his work on curved pipes (Narashimha and Sreenivasan 1973). The most common cause for re-laminarization is an intense favorable pressure gradient, as it has been widely studied (Launder 1964; Moretti and Kays 1965; Schraub and Kline 1965; Patel and Head 1968; Badri Narayanan and Ramjee 1969). The subject still attracts the scientific community, such as the work of Nguyen (2012), in which re-laminarization in supersonic corners are treated by numerical simulation under theoretical discussions about turbulent models.

Therefore, only more tests with high variation of Reynolds numbers could adequately assess this issue. In this case, larger models tested in higher transonic installations, or the possibility of high variation of pressure during tests, would be necessary.

At the end of the supersonic region, a shock wave is formed to force the flow back to subsonic conditions. When the shock wave reaches the boundary layer, depending on its condition (whether laminar, turbulent or re-laminarized), the interaction region plays an important role in the flow pattern. Figure 2 also shows the increase of the boundary layer thickness as it responds 
to the strong pressure increase imposed by the shock wave, causing a possible recirculation bubble. The subsonic region of the boundary layer transmits the pressure rise in the opposite direction of the main flow, causing a growth in boundary layer thickness in some extent into the supersonic region (3). This finally produces compression waves, as the supersonic external flow has to change its direction. Curved lines represent the compression waves. The lines are not straight due to the existence of other compression waves interacting with them, not shown in the picture, because they represent a quite complex flow (Babinsky and Harvey 2011).

Actually, the details of shock wave interaction with laminar or turbulent boundary layers result in rather complex mechanisms. Nevertheless, the present research obtained good results primarily on the investigation of the general flow field pattern, without focusing on the specific details of the interaction of the shock wave with the boundary layer.

To assess experimental data, a test campaign was undertaken in IAE’s TTP (Túnel Transônico Piloto; Portuguese for Pilot Transonic Wind Tunnel), from 2013 to 2015, varying Mach number and pressure, and using five selected typical model configurations. The present work describes only the main results obtained by varying Mach numbers from subsonic to low supersonic, using two experimental approaches to assess the flow field, by Schlieren images, and the pressure distribution on the model, by PSP technique.

The discussions presented here are restricted to the characterization of the most relevant phenomena observed using the two experimental techniques in each different type of the geometry of the frontal region of the model, such as: shock waves positioning; intensity of property gradients on the model surface; and effects indicative of density variation observable by the Schlieren in the flow field. This characterization is very useful, in the preliminary vehicle phase, for defining the criteria for choosing a particular configuration over another. It is important to note that, due to different missions to be considered in each type of vehicle design (long-range or short-range missiles, and launch vehicles), other criteria that are beyond the scope of this research work should be considered as well.

\section{METHODOLOGY}

The experiments were overtaken in the TTP, a small but still modern installation, built in a scale of $1 / 8^{\text {th }}$ from an industrial transonic facility projected in the 1980s by IAE (Falcão Filho et al. 2009). One Schlieren optical system assessed qualitative density distribution over the models, and the PSP technique measured, quantitatively, the pressure distribution on the models. The installation has been used to support several aerodynamic research works in IAE regarding space vehicle development (Falcão Filho et al. 2011; Avelar et al. 2018; Medeiros et al. 2016).

\section{PILOT TRANSONIC WIND TUNNEL}

The pilot facility is operational and maintains the same technological concepts of the original industrial project. Figure 3 shows a diagram with the main components of the TTP installation. A two-stage axial compressor (2), with a main power of $830 \mathrm{~kW}$, continuously drives the tunnel circuit, attaining a Mach number range from 0.2 to 1.1 (arrows indicate the flow direction into the aerodynamic circuit). An injection system (7,8 and 9) supplies compressed air from reservoirs (10) to extend its operational envelope for at least 30 seconds, in order to achieve a Mach number up to 1.3. The tunnel has also automatic controls of speed, acting especially on the compressor rotation (2), and pressure, through an auxiliary compressor (12), as well as automatic control valves (13 and 14) of temperature, through the cooler (3), and humidity, through the dryer (15). This way, it is possible to accomplish stable conditions of Mach and Reynolds numbers related to the test section, which is installed into

a plenum chamber (6). 


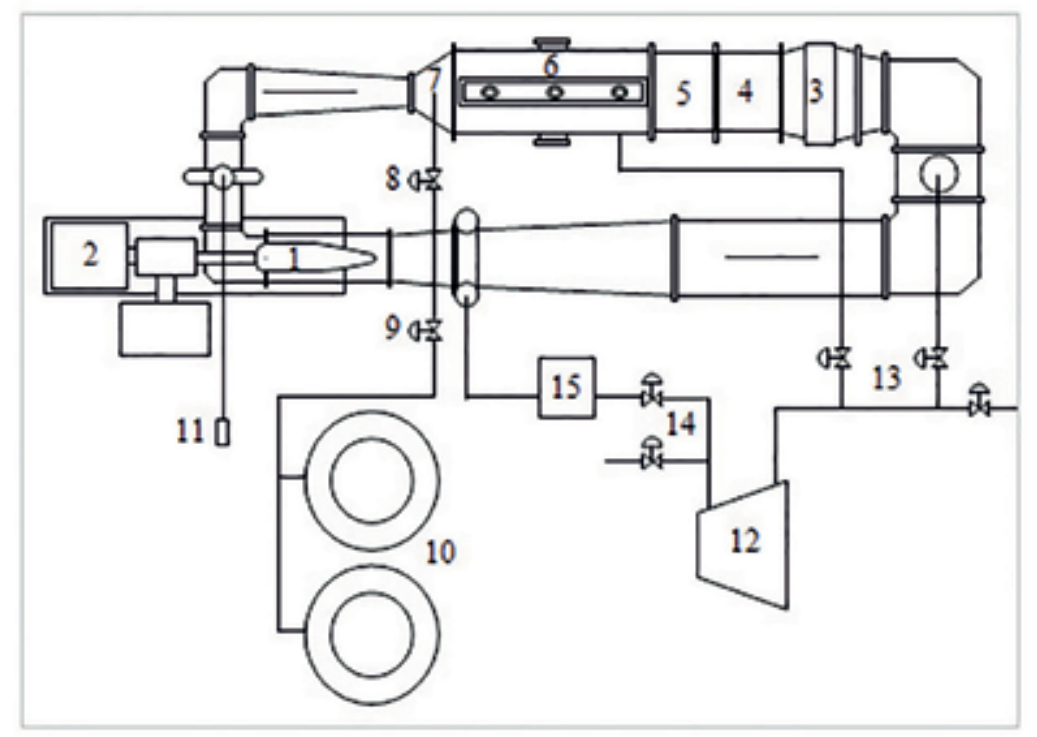

Figure 3. Diagram of TTP installation, with its main components: (1) main compressor; (2) electric motor; (3) cooler; (4) stilling chamber; (5) contraction; (6) plenum chamber, which involves the test section; (7) injectors; (8) injector system control valve; (9) safety valve; (10) reservoirs; (11) exhaustion valve; (12) auxiliary compressor; (13) admission valves; (14) discharge valves; and (15) dryer.

The plenum chamber (6 in Fig. 3) involves the highest speed components of the aerodynamic circuit. Figure 4a shows (4a) a diagram with the elements into the plenum chamber; and (4b) the plenum chamber open in the real installation. After accelerating in the contraction sector ( 5 in Fig. 3), the flow is further accelerated by the first throat to achieve its final condition at the test section, where the model is installed. The test section of the tunnel has $0.30 \mathrm{~m}$ of width, $0.25 \mathrm{~m}$ of height, and $0.81 \mathrm{~m}$ of length, and its walls have 12 longitudinal slots, representing $5 \%$ of the open area. The slots reduce wall interferences, and transonic flow conditions are well established. The plenum chamber allows the pressure to stabilize along the longitudinal slots, simulating far field conditions on the walls. Flaps at the end of the test section make a fine tune of the mass through the slots (curved arrows), whilst the second throat helps controlling shock wave location during supersonic tests (Falcão Filho el al. 2009).

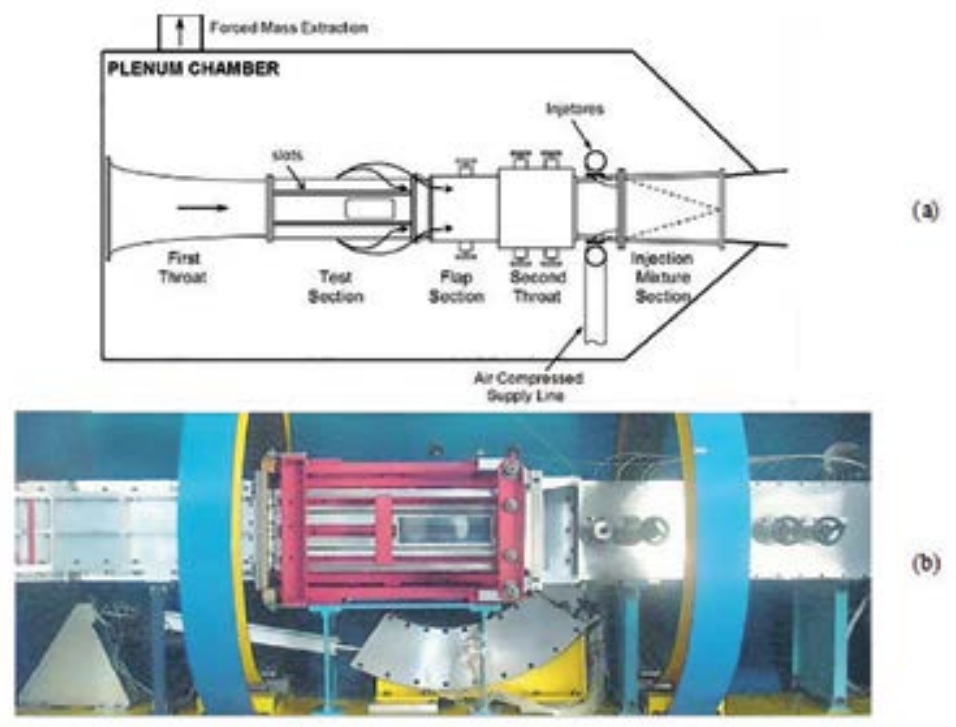

Figure 4. Diagram with internal parts of the plenum chamber (a); and the internal view of the real installation - the test section is supported by red structural frames (b). 


\section{THE MODELS}

Five different forebody configurations were considered, as they can be connected to a common interchangeable cylindrical body, described by the illustration in Fig. 5. The intermediate piece has its internals specially designed for installation of an internal balance, in order to measure aerodynamic forces. Figure 5 a shows the complete cone-cylinder model, defined by its half-opening angle $\delta$ of $10^{\circ}$, and, from Fig. $5 \mathrm{~b}$ to $5 \mathrm{e}$, the other fronts are displayed. Table 1 describes the main dimensions of the models, made non-dimensional by the transversal diameter of the body, $D=0.0273 \mathrm{~m}$. The forebody geometries are defined based on Chin (1961).

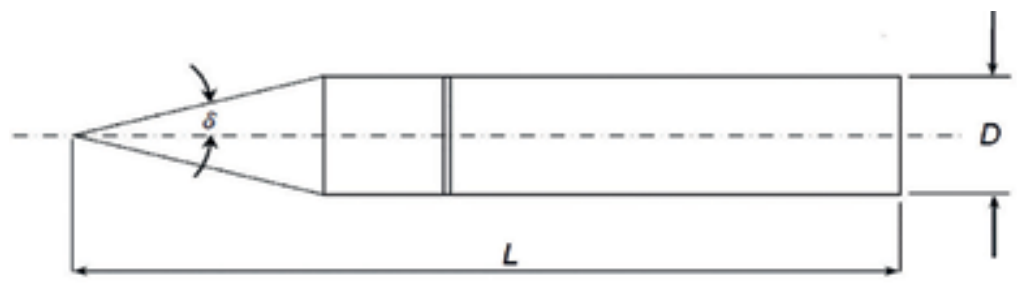

(a)

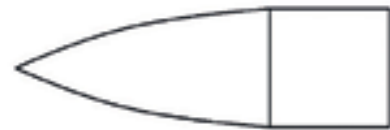

(b)

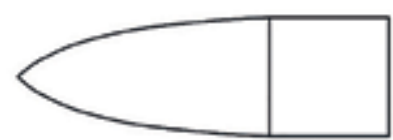

(c)

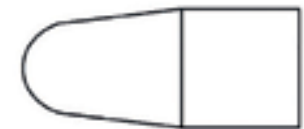

(d)

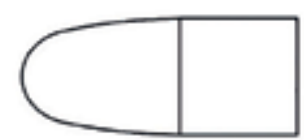

(e)

Figure 5. Aerodynamic model conceptions used in the experimental tests in wind tunnel: (a) conecylinder; (b) tangent-ogive; (c) Haak; (d) tangent-hemispheric; and (e) hemispheric.

Table 1. Main dimensions of the models.

\begin{tabular}{|c|c|c|c|}
\hline Conception & $\begin{array}{l}\text { Front length } \\
L / D\end{array}$ & $\begin{array}{l}\text { Total length } \\
\qquad L_{t} / D\end{array}$ & Design characteristics \\
\hline Cone-cylinder & 4.029 & 8.132 & Defined by the cone opening half angle of $10^{\circ}$. \\
\hline Tangent-ogive & 3.956 & 8.059 & Defined by the ogive radius of $R_{\mathrm{o}} / D=8.290$. \\
\hline Haak & 3.957 & 8.060 & $\begin{array}{l}\text { Defined by the parameter } C=1 / 3 \text {, corresponding to } \\
\text { minimum drag related to length and volume. }\end{array}$ \\
\hline Tangent-hemispheric & 2.245 & 6.348 & $\begin{array}{l}\text { Blunt front, defined by the front radius of } R_{\mathrm{f}} / D=0.421 \text { and } \\
\text { the setting radius of } R_{\mathrm{s}} / D=2.955 \text {. }\end{array}$ \\
\hline Hemispheric & 2.245 & 6.348 & $\begin{array}{c}\text { Blunt front, defined by the front radius of } R_{\mathrm{f}} / D=0.421 \text { and } \\
\text { the frustum cone angle of } 6.62^{\circ} \text {. }\end{array}$ \\
\hline
\end{tabular}

Figure 6 shows the test section without the lateral wall, where it is possible to see the cone-cylinder model installed in the sting fixing structure. The figure also shows an exploded view with its three parts: the forebody (Fig. 6a), the internal intermediate piece used to fix the internal balance (Fig. 6b), and the cylindrical part (Fig. 6c). 


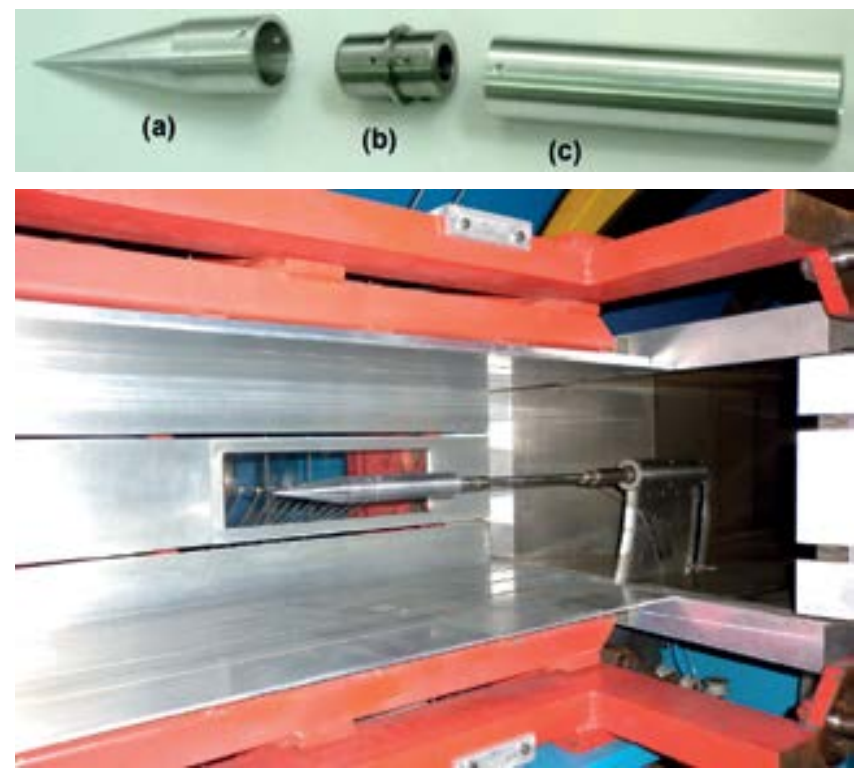

Figure 6. Cone-cylinder model installed in the TTP test section and in an exploded view, showing the forebody (a); the internal intermediate piece (b); and the cylindrical part (c).

\section{SCHLIEREN SYSTEM}

A conventional Schlieren optical system was used to get insights about the flow field patterns over the surface of the model. The principle of the Schlieren method is based on the flow visualization of the light refraction caused by local density gradients in the flow, allowing observation of non-homogeneities, such as shock waves and shock wave-boundary layer interactions. More details about Schlieren technique can be found in Merzkirch (2007).

The main components of the Schlieren system used in the present research were two 6"diameter parabolic mirrors, two 8" diameter flat mirrors, one knife-edge, a Sony cyber-shot DSC-HX300, and a light source consisting of a point source of white light with a diverging beam. The light source is located at the focal point of a first parabolic mirror, which reflects the light beam into parallel rays, directed, by their turn, to pass through the test section windows. Some of the parallel rays are eventually distorted as they cross through the test section region, and are collected by the second parabolic mirror, which converges them to its focal point, where the knife is located to vary the image contrasts. After this point, the camera is positioned to allow a focused image. The flat mirrors are used to make a more compact assembly.

\section{PRESSURE-SENSITIVE PAINT SYSTEM}

PSP technique was used for getting field pressure distribution over the models surface. Combined with the Schlieren images, the PSP results allowed a deeper understanding of the complex flow patterns identified on the models surface.

The advantage of PSP, in comparison to the traditional method of pressure taps, is that it provides a solution for pressure measurements on the surface of a model without the transducers and tubing, giving higher resolution and the possibility to access any area of interest on the model surface in a non-intrusive way, with a relatively low cost. The PSP technique is well documented in the literature, and a detailed description of the technique can be found in Liu and Sulivan (2005). The working principle of this technique is based on an oxygen quenching process, in which excited molecules are deactivated by oxygen, generating different degrees of luminosity on the model surface. The final pressure map is obtained using image processing techniques. The PSP paint is composed of an oxygen-permeable polymer binder containing luminescent oxygen-sensitive molecules. When illuminated with light at an appropriate wavelength, the luminescent molecules become excited electronically to an elevated energy state. These molecules can decay to the ground state through a radioactive process, luminescence, or a non-radioactive way through release of heat. In some materials, oxygen can interact with the luminescent molecules, such that the change to the ground state can be non-radioactive, being also able to take place by colliding with an oxygen molecule - a process known as "oxygen quenching". 
A PSP system is composed of PSP paint, an illumination source, an image detector, a scientific camera, and a long-pass filter. The PSP paint is distributed over the model surface and then illuminated by the excitation source, making the PSP to luminesce. The luminescent intensity from the PSP is recorded by the detector, and converted to pressure using a previously obtained calibration.

Here, the Binary FIB PSP, by Innovative Software Solutions Inc." (ISSI) was used. The Binary FIB is a dual-luminophore pressure-sensitive paint (i.e., data are acquired from two distinct luminescent dyes, and these signals are used to compensate for errors caused by model displacement and deformation, as well as temperature). One dye is pressure and temperature sensitive, and the other one is temperature sensitive only. The ratio of the signals from the two dyes allows the temperature sensitive signal to be isolated from the pressure sensitive one. Using the Binary FIB, the PSP experimental setup consisted of a LM2X LED Lamp of 400 nm wavelength; a PSG-2 pulse generator; the painted model itself; a computer for data acquisition and control; and a PSP-CCD-C color camera. This camera does not have optical filters in front of its lens; instead, the filtering is applied on the chip using a Bayer filter, which separates the two spectrally different signals from the Binary PSP, allowing binary PSP data to be acquired using a single image acquisition. The PSG-2 is a four-channel pulse-delay generator, which enabled the camera to be controlled from the control room of TTP, via trigger signals. Communication between the camera and the computer was made via an Ethernet connection. All camera parameters could be controlled via software, and images were transferred to the computer in real time. A detailed description of the Binary FIB PSP measurements in the TTP can be found in Fanini Leite et al. (2017).

\section{RESULTS}

Initial results using Schlieren method will be presented for all models followed by some selected study cases to compare them with results using PSP. Since the tests were undertaken in different days, and because of wind tunnel operating constrictions, unfortunately, Mach number settings could not always be precisely repeated, and an approximation in the tunnel control was considered, adjusting total pressure, total temperature, and Mach number results in the Reynolds number at the test section. In Fig. 7 it is possible to see the variation of the Reynolds number with Mach number at the test section, determined by considering the model diameter as the characteristic length, a total pressure of $80 \mathrm{kPa}$, and a total temperature of $300 \mathrm{~K}$.

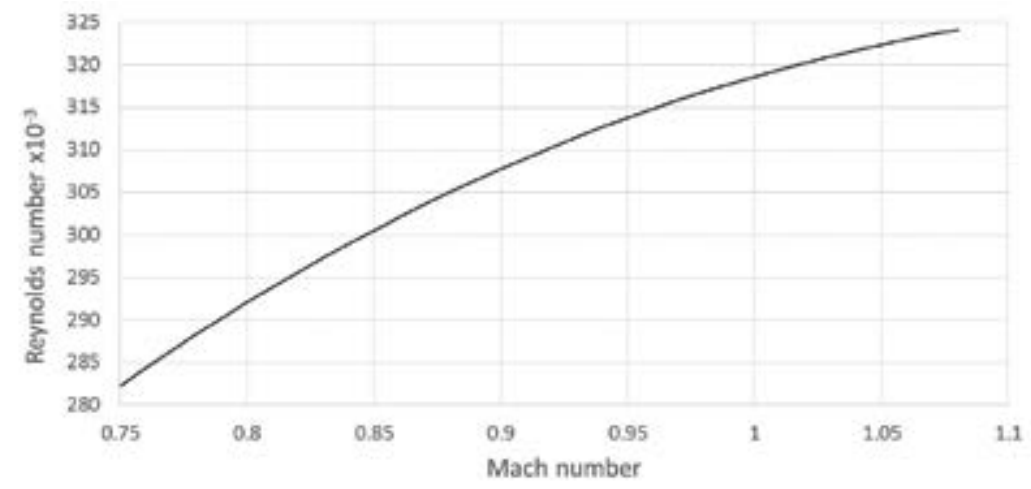

Figure 7. Reynolds number varying Mach number for stagnation pressure of $80 \mathrm{kPa}$, stagnation temperature of $300 \mathrm{~K}$, and considering the characteristic length as the model diameter of $27.3 \mathrm{~mm}$.

\section{SCHLIEREN IMAGES FOR CONE-CYLINDER MODEL}

Figure 8 shows Schlieren image results for Mach number ranging from 0.75 to 1.08 for the cone-cylinder model, with $0.78 \%$ of blockage area ratio. Insignificant wall interference is expected, as the blockage area ratio is below 1\% (Pope and Goin 1978).

For Mach number 0.75, no density gradient is observed, and, for Mach number 0.80, a tiny region of contrast happens at the corner. Therefore, it can be presumed that the critical Mach number occurs between these two Mach number values. The image for Mach number 0.82 confirms this fact, by showing a little more pronounced region of contrast, in which it is possible to observe a 
triangle-like region, delimited by a frail line, starting at the corner and going downward (in the figure), until reaching the vertical line, which represents a shock wave that starts at some point on the model surface.

This triangle-like region enlarges as the Mach number increases, and its shape becomes more evident. For Mach number 0.90, it is quite evident that the shock wave propagates further (downward in the figure).

The line starting at the corner is noteworthy. Just after the flow becomes supersonic, it experiences strong density gradient caused by the supersonic expansion, which is represented in the image by this frail line starting at the corner. The actual sonic line, which defines the inlet boundary of the supersonic region, occurs a little bit earlier than this line, and it is not revealed in the image. To assess experimentally the occurrence of the phenomena, it would be necessary to map the whole field by plotting constant density lines, which would be possible only with advanced technology, like PIV (Particle Image Velocimetry). However, due to accessibility and operational restrictions, this is not possible in TTP.

For Mach numbers 0.93 to 0.99 , some patterns can be seen within the supersonic region, close to the shock wave foot, which are related to the interaction of the shock wave with the boundary-layer.

For Mach number 0.99, the foot of the shock wave has a lambda formation, indicating a significant increase in the boundarylayer thickness, and a consequent formation of compression waves. The growing of the boundary layer forces the supersonic flow to change its direction, creating the compression waves, which will finally merge in the shock wave.

For Mach number 1.00, the lambda formation becomes quite larger. The great change in the shock wave formation is remarkable about Mach number 1.00. From Mach numbers 0.97 to 1.00, the shock wave location advances approximately 0.7 diameters, and the lambda formation developes its length from zero to 0.47 diameters. This is an impressive variation, since the Mach number increased only 0.03 .

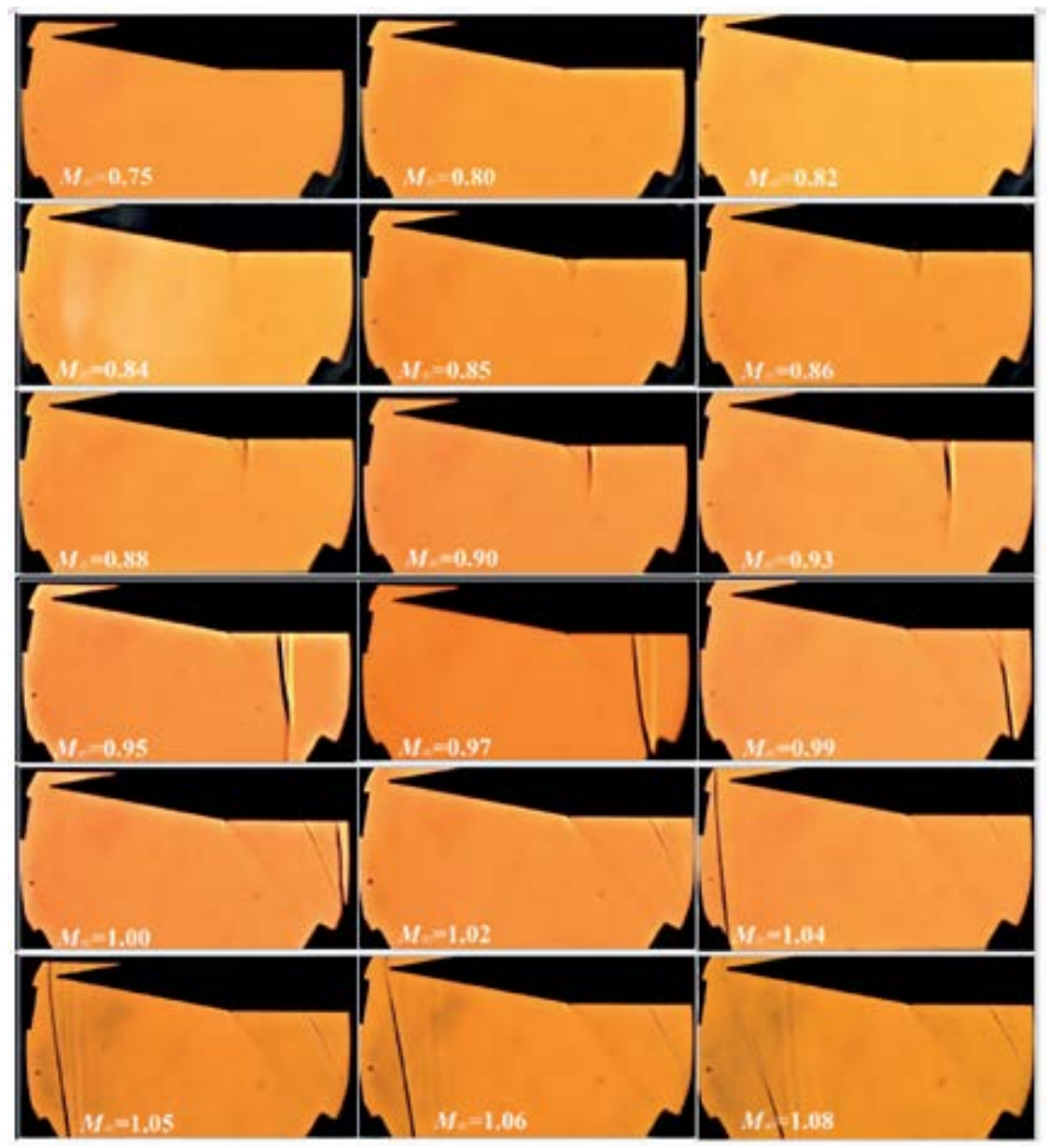

Figure 8. Schlieren images for model cone-cylinder forebody with blockage area ratio of $0.78 \%$, for stagnation pressure of $80 \mathrm{kPa}$ and stagnation temperature of about $300 \mathrm{~K}$. 
Unfortunately, from Mach number 1.02, the shock wave goes out of the viewing window. The formation of a bow shock wave can be then seen in front of the model, which would be attached to the model tip for Mach numbers above approximately 1.05 for this particular body geometry, according to literature (Staff 1953). For Mach number 1.06, it is possible to see the shock wave line practically straight, indicating that it is attached to the model tip.

\section{SCHLIEREN IMAGES FOR TANGENT-OGIVE MODEL}

Figure 9 shows Schlieren image results for the model tangent-ogive, with a blockage area ratio of $0.78 \%$ for a Mach number ranging from 0.95 to 1.08. Although available, the lower Mach number results were omitted, since they showed no pattern. This is due to the fact that the model has aerodynamic shape, interfering little with the surrounding flow field, in evident contrast with the results from the cone-cylinder model.

For Mach number 0.95, it is possible to see the initial formation of what could be thought of as multiple incipient weak shock waves interacting with the boundary layer. This fact indicates that the critical Mach number condition has taken place at Mach number condition a little lower than 0.95. For higher Mach numbers, these weak shocks become stronger, and end up collapsing in a single strong normal shock wave, as can be seen in the Schlieren image for Mach number 0.99.

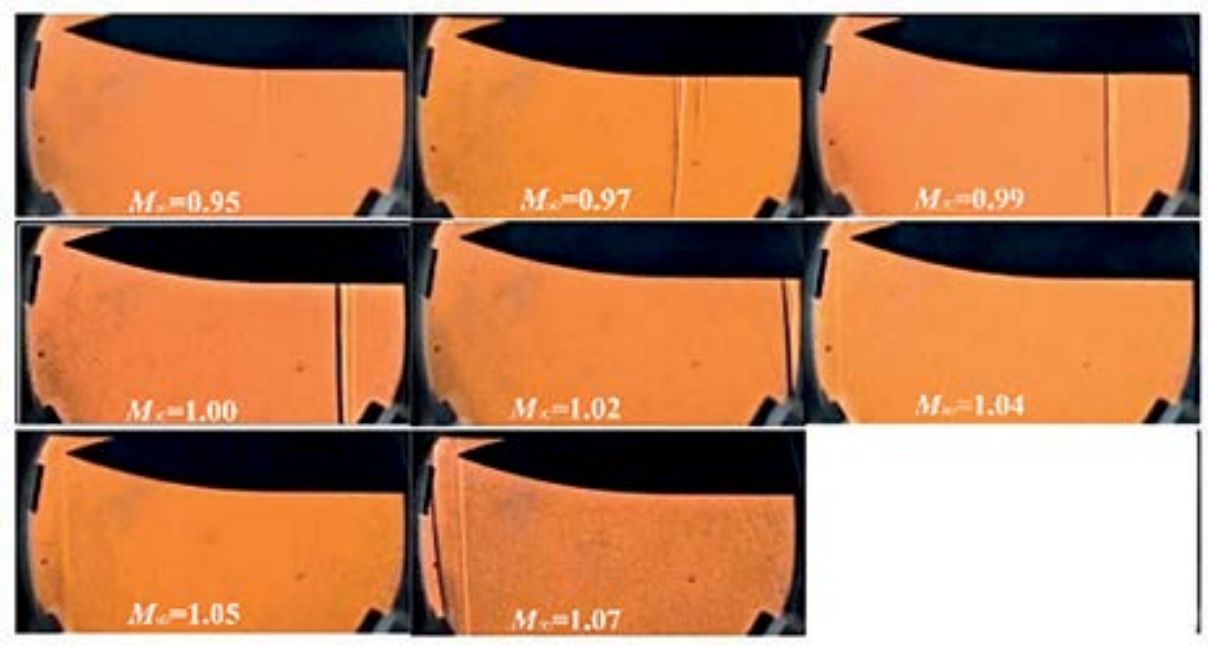

Figure 9. Schlieren images for model tangent-ogive forebody with a blockage area ratio of $0.78 \%$ for a stagnation pressure of $80 \mathrm{kPa}$ and a stagnation temperature of about $300 \mathrm{~K}$.

In this case, the shock wave foot does not have the lambda formation. An issue arises from the reason why lambda formation occurred in the cone-cylinder case. One possible explanation is related to the occurrence of flow re-laminarization. In the cone-cylinder, as the flow passes abruptly by the corner, it experiences a very strong expansion with strong favorable pressure gradient, which accelerates the flow and tends to laminarize the boundary layer. Therefore, the shock wave formed possibly interacts with typical laminar boundary layer.

On the other hand, in the tangent-ogive case, the flow always undergoes smooth changes, and the boundary layer develops continuously from laminar to turbulent condition. Therefore, for tangent-ogive model, the shock wave possibly interacts with boundary layer more typically turbulent.

For higher Mach numbers, the shock wave impinging on the model moves downstream, leaving the viewing region, and a bow shock wave in front of the model begins to appear. In this case, the shock wave does not attach to the tip of the model for all images, since the model tip has an angle of $40^{\circ}$ - twice the angle for the cone-cylinder tip model. Hence, this is a case in which the theoretical minimum Mach number for the shock wave to be attached to the model tip is 1.21, according to Staff (1953).

\section{SCHLIEREN IMAGES FOR HAAK MODEL}

Figure 10 shows Schlieren image results for Haak model, with a blockage area ratio of $0.78 \%$, for a Mach number ranging from 0.95 to 1.08. Although available, lower Mach number results were not shown, since they showed no pattern, as the model has aerodynamic 
shape. Because Haak model is lesser aerodynamic than the tangent model, some small differences could be perceived from the results compared to the last case.

In general, one can observe that the shock wave formations are slightly more pronounced than in the tangent-ogive model, and again the lambda formation at shock wave foot is not present. The Schlieren images show thin oblique lines indicating expansion waves. The normal shock wave impinging on the model surface determines the outlet frontier of the supersonic region.

The detached bow shock wave in front of the model is further away than that in the previous case, because the angle of the surface at the Haak model tip is much higher than in the tangent-ogive model.

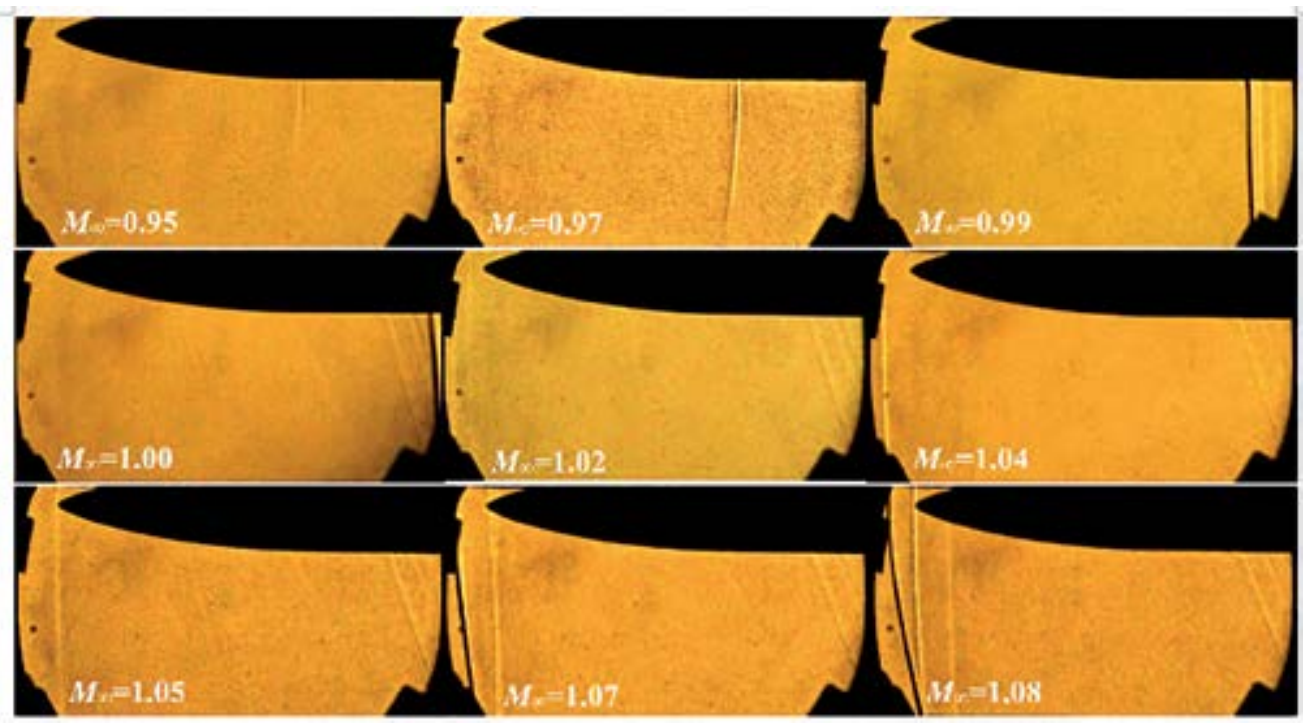

Figure 10. Schlieren images for model Haak forebody with a blockage area ratio of $0.78 \%$ for a stagnation pressure of $80 \mathrm{kPa}$ and a stagnation temperature of about $300 \mathrm{~K}$.

The small difference observed in the results between these two aerodynamic models (tangent-ogive and Haak) could be explained by their geometric characteristics, as described by Fig. 11.

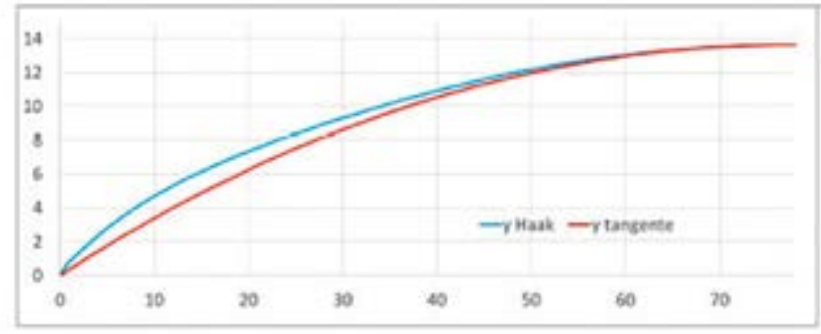

(a)

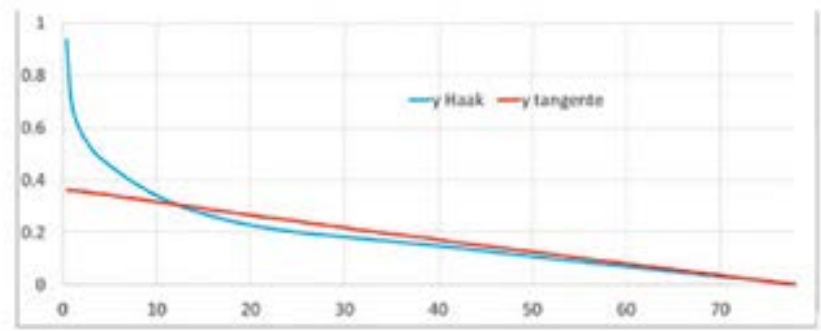

(b)

Figure 11. Comparison between models with tangent-ogive and Haak fore bodies: (a) geometries; (b) first derivatives. 
Figure 11a compares the geometric dimensions of the forebody along the length, and Fig. 11b its local first derivative values. The Haak has less aerodynamic shape, as some level of bluntness can be seen at the model tip, being more evident by the first derivative values. The total initial angle for tangent-ogive model is $40^{\circ}$, whilst, for Haak, it is $86^{\circ}$. This characteristic is sufficient to make the shock wave to appear in the images a little stronger in Haak than in the tangent-ogive. Observing the results from both models, for Mach number 0.97 , it is notorious the secondary shock formation in the tangent-ogive model, indicating that the first shock formation is less intense.

\section{SCHLIEREN IMAGES FOR HEMISPHERIC MODEL}

Figure 12 shows Schlieren image results for Mach numbers from 0.75 to 1.08 for hemispheric forebody model with $0.78 \%$ of blockage area ratio. Although it is expected unimportant wall interference, because it is lower than $1 \%$, it has potentially more chance to show wall effects, given the bluntness of the forebody shape.

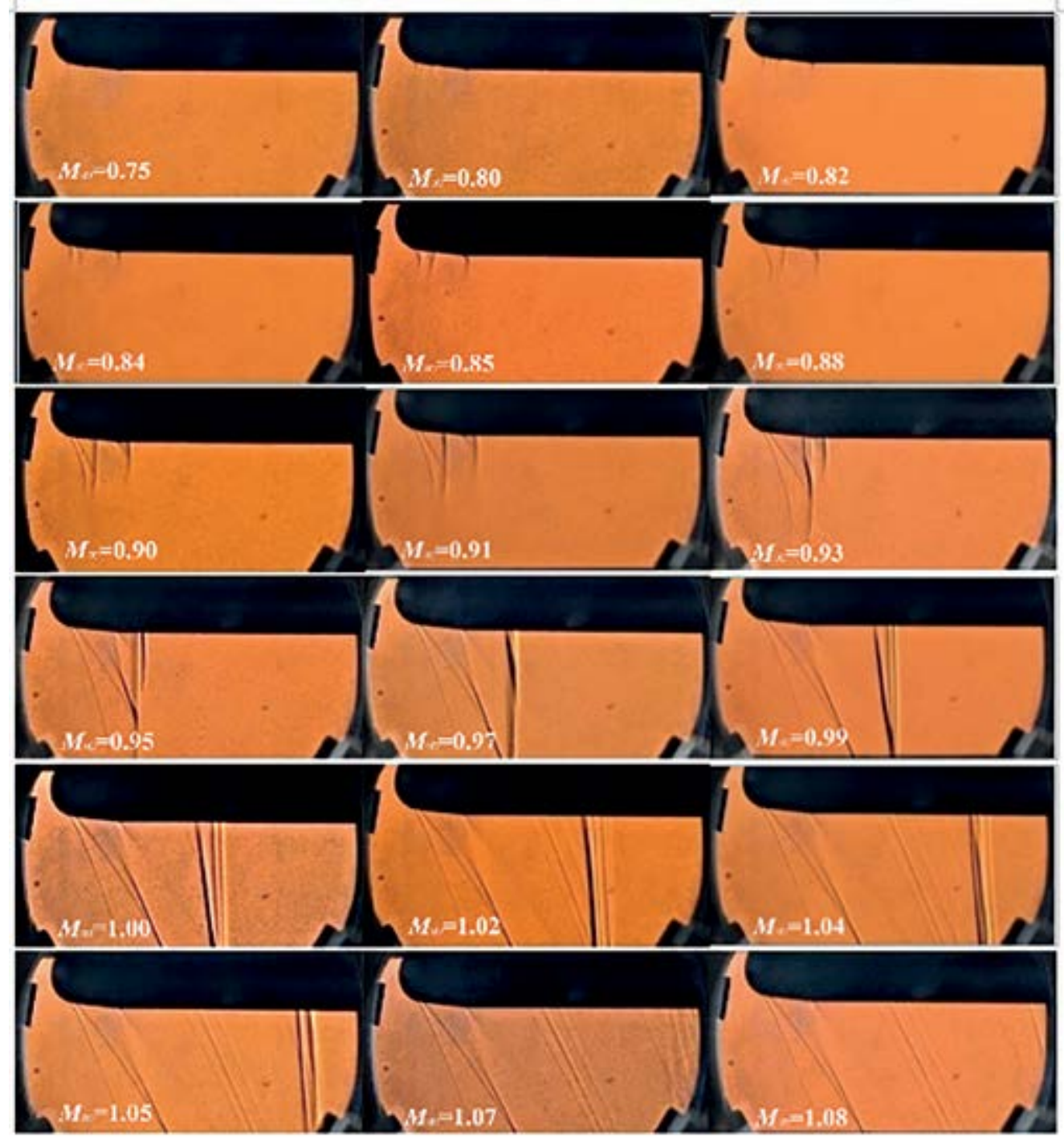

Figure 12. Schlieren images for model hemispheric forebody with a blockage area ratio of $0.78 \%$ for a stagnation pressure of $80 \mathrm{kPa}$ and a stagnation temperature of about $300 \mathrm{~K}$. 
For Mach number 0.75, virtually nothing could be observed, but, for Mach number 0.80, it was possible to identify incipient patterns, like multiple weak shock waves, close to the nose tip, and a small formation at the beginning of the cylindrical part.

For a better understanding, three regions can be identified, with distinct geometries alongside the model, namely: (1) a hemispheric region in the very front of the model; (2) a frustum cone, ending with a corner; and (3) a cylindrical part. For Mach number 0.82 , the flow formations are more evident, and two evident regions of acceleration can be seen, one just at the beginning of the frustum cone and another at the beginning of the cylindrical part.

As the main flow accelerates from Mach number 0.84 to 0.88 , these structures grow and become better defined. For example, for Mach number 0.85 , it is possible to define three triangle-like regions, with the same pattern, two at the frustum cone and one at the corner.

As the two triangle patterns at the beginning of the frustum cone are very close to one another, when the flow is further accelerated, they interact with one another, giving rise to a new larger pattern, as shown for Mach numbers 0.90 and 0.91. For Mach number 0.93, it is possible to observe how this new pattern increases and touches the pattern at the corner, even embracing it for Mach number 0.95 , resulting in a very complex supersonic region.

Finally, a strong and quite evident shock wave is formed for Mach number 0.97, being propagated downstream for higher Mach numbers. It is noteworthy that the complex pattern created inside the supersonic region is kept practically unchanged up to the shock wave location.

\section{SCHLIEREN IMAGES FOR TANGENT-HEMISPHERIC MODEL}

Figure 13 shows Schlieren image results for Mach numbers ranging from 0.88 to 1.07, for a tangent-hemispheric forebody model with $0.78 \%$ of blockage area ratio. The selection of Mach numbers was made to compare the most evident flow patterns with the results of the hemispherical model.

Important differences already appear for Mach number 0.88. In the tangent-hemispheric model the third triangle-like pattern occurs before the corner, and the lines are smoother than in the hemispheric model. Indeed, a weak formation at the corner occurs at Mach number 0.90 , which is soon superimposed by the formations that start and are expanded from the beginning of the frustum cone.

For Mach number 0.93, it can only be observed a curved line at the beginning of the frustum cone, and a diffused formation at the beginning of the cylindrical part. This formation will result in a normal shock wave, as one can see for Mach number 0.95 .

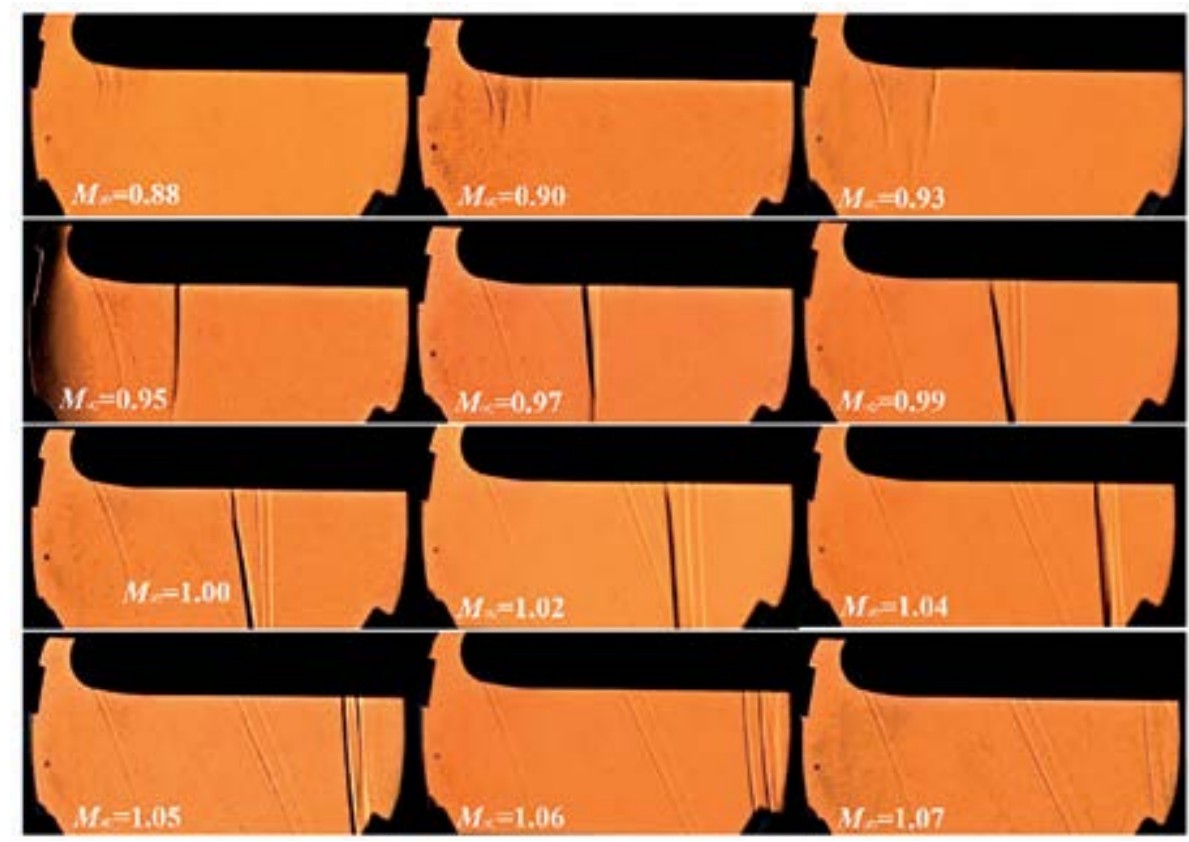

Figure 13. Schlieren images for model tangent-hemispheric forebody with a blockage area ratio of $0.78 \%$ for a stagnation pressure of $80 \mathrm{kPa}$ and a stagnation temperature of about $300 \mathrm{~K}$. 
It is remarkable to realize how simple is the flow pattern for Mach numbers higher than 0.95. A smooth desirable flow behavior was achieved only because the geometry conformed perfectly, resulting in a continuous change of the first derivative of the model surface (particularly, in two points: one determined by the interface between the end of the hemispheric and the beginning of the frustum cone, and the one determined by the interface between the end of the frustum cone and the beginning of the cylindrical part).

The simpler geometry, in terms of construction, defined by the straight line of the frustum cone in the hemispheric model, results in a much more complex flow, with undesirable flow properties distribution on its surface.

\section{COMPARISONS BETWEEN SCHLIEREN IMAGES AND PSP TECHNIQUE}

Although Schlieren images can expose the field about a tested model, making evident the shock wave positioning, they fail to quantify the flow properties, which are very important for designing real flight prototypes. In this case, PSP technique proves to be very useful for the determination of the pressure distributions, and gradients on the surface of the model. Due to technical limitations, it was not possible to present drag calculations based on the integration of pressure distribution over the models.

Three study cases were selected to investigate the pressure distribution on the model surface, using PSP technique, and comparing it with the qualitative outer density field obtained from Schlieren images, in order to verify the consistency of the two approaches. These forebody selected cases are: (1) cone-cylinder for Mach number 0.95; (2) tangent-ogive for Mach number 0.99; and (3) tangent-hemispheric for Mach number 0.99. Unfortunately, the nearest Mach number condition available for the cone-cylinder case was 0.95 .

Since the models have different geometries, an appropriate criterion was adopted to compare the results, which was to position the streamwise axis origin in the point where the geometry becomes cylindrical, regardless the construction detail of each model. All graphics use this origin definition.

Figure 14 shows comparison between results from PSP technique and Schlieren image for cone-cylinder model with a blockage area ratio of $0.78 \%$, and for Mach number 0.95 . This figure is formed by three juxtaposed images, namely, from top to bottom: (1) a graphic with streamwise pressure distribution from PSP technique, in terms of the relation between static pressure and stagnation pressure $\left(\mathrm{p} / \mathrm{p}_{0}\right)$ along the centerline distance, made nondimensional by the model diameter; (2) PSP two-dimensional image with the palette of colors; and (3) a Schlieren image.

The PSP image and the pressure distribution graphic were adapted to the dimensions of the Schlieren image in order to attain the same scale. Only one-half of the PSP image is represented to combine with the other half part of the Schlieren image. The same idea was used in all selected cases shown hereafter.

For this case, Silva (2017) reported other experimental results, and they are all represented in the graphic as: solid black line (the present PSP result); black diamond (the present pressure tap result); cross (experimental results from AEDC $16 \mathrm{~T}$ [0.008\% of BR]); and hollow circle (experimental results from MSFC 14 in [1.47\% of BR]), where BR stands for blockage ratio.

A perturbation in the graphic at $x / D \approx-1.9$ was caused by the transition strip fixed close to the model tip in order to force transition to turbulent regime, simulating higher Reynolds number condition. This same pressure perturbation is observed whenever the transition strip is used. The presence of the transition strip causes local flow acceleration, with consequent static pressure drop, that is soon reestablished, as can be seen in Fig. 14. Obviously the transition strip causes increased drag that is not observable by PSP technique, which measures static pressure levels.

The black diamond point at $x=-1.34$ represents the result with conventional pressure tap technique, as obtained by means of a pressure transducer remotely installed and connected through flexible capillary hoses. Usually, PSP technique requires one or two pressure tap measurements to be used for comparison, as some unexpected effect, like illumination or ink wear, may affect the level of the PSP curve. In this particular case, no adjustment in the curve was necessary, and the results were practically coincident at the measurement point. 


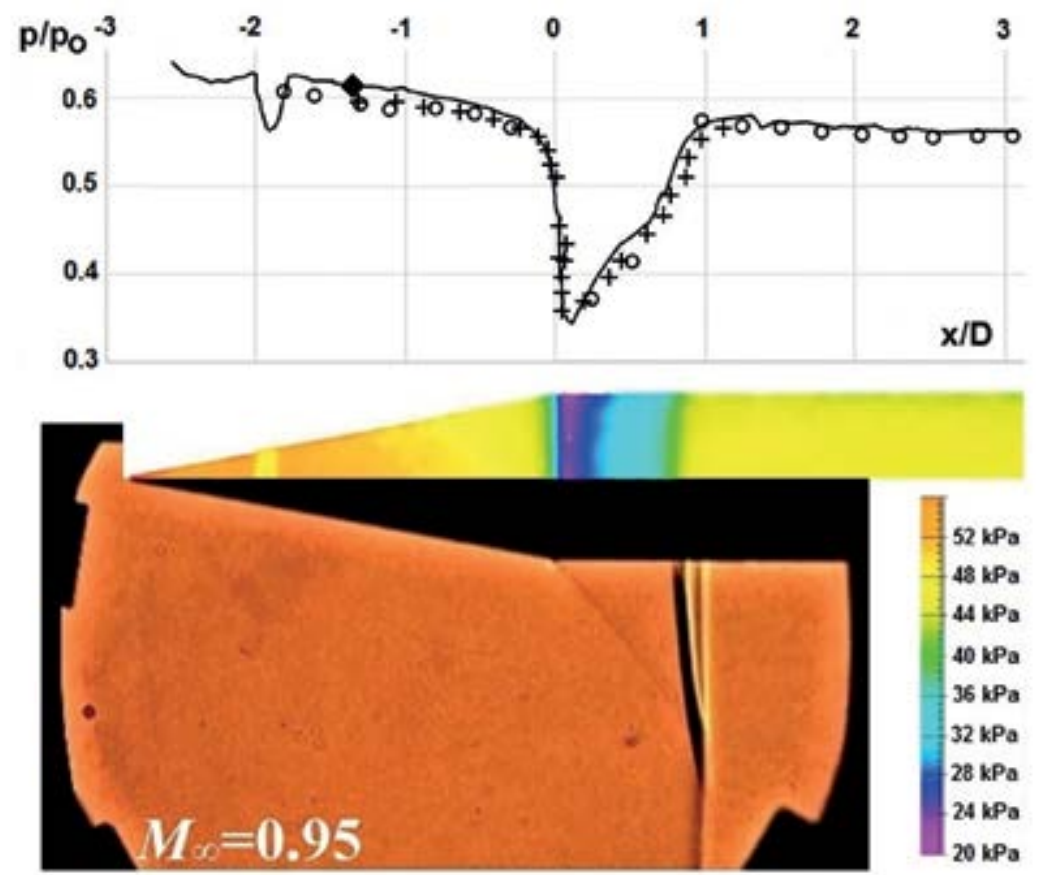

Figure 14. Comparison of results from PSP technique and Schlieren image for cone-cylinder model with a blockage area ratio of $0.78 \%$ for a stagnation pressure of $80 \mathrm{kPa}$ and a stagnation temperature about $300 \mathrm{~K}$. Conventions

in the graphic are: solid line = PSP result; black diamond = pressure tap result; cross = experimental results from AEDC 16T (0.008\% of BR); hollow circle = experimental results from MSFC 14 in (1.47\% of BR).

In the cone region, the pressure ratio starts a little higher than the undisturbed condition value, and it decreases slowly along the cone, influenced by an expansion that occurs at its end. This is a particular characteristic of pressure propagation in subsonic conditions. At the corner, there is a strong supersonic expansion, and the pressure ratio drops abruptly to $p / p_{0}=0.34$, corresponding to the maximum Mach number of 1.34. After the expansion, the pressure will necessarily rise again, to achieve an undisturbed condition downstream the model. This pressure increase occurs in two distinct steps, or regions, as can be seen in the graph.

The first step, which goes from the maximum expanded point at $x / D \approx 0.1$ to the point at $x / D \approx 0.7$, the pressure rises gradually to $p / p_{0}=0.46$, through a sequence of compression waves, corresponding to an estimated Mach number of 1.11.

In the second step, which corresponds to a shock wave occurrence, the pressure rises more abruptly to $p / p_{0}=0.57$. The reason why a more precise normal shock wave does not occur is the three-dimensional geometry characteristic, which includes quite complex effects of propagation and interactions of expansions and shock waves.

It is interesting to realize that the pressure ratio immediately after the shock wave is still above the undisturbed flow condition. The pressure value still undergoes some change until the final condition of the undisturbed flow, of $p / p_{0}=0.559$, which corresponds to undisturbed Mach number condition of 0.950 . This fact may be due to adjustment related to effects experienced locally by the boundary layer. In general, it can be observed that the shock wave located approximately at $x / \mathrm{D} \approx 0.8$ was practically captured by both techniques employed (PSP and Schlieren).

Figure 15 shows a comparison between PSP technique and Schlieren image for tangent-ogive model with a blockage area ratio of $0.78 \%$, and for a Mach number of 0.99 . The graphic also shows the pressure tap result (in red diamond) at $x / D=-1.27$, which had good agreement with the curve obtained by the PSP method, and no adjustment in PSP curve was necessary. A transition strip fixed at about $x / D=-2.50$ was used to force transitioning to turbulent regime, simulating high Reynolds conditions.

While, in the cone-cylinder model, the pressure varied very little in the cone, followed by a sudden drop at the corner, in the tangentogive model, the pressure undergoes a gradual decrease until reaching the minimum value of $p / p_{0}=0.45$ at $x / D \approx-0.2$, which corresponds to the maximum expansion condition. The estimated Mach number at this point was 1.13, which is much lower than the minimum 
value found for the cone-cylinder model (1.34), making it clear that the tangent-ogive interferes much less with the mean flow. It is also important to observe that, in the cone-cylinder case, the undisturbed Mach number condition for the experience was 0.95 , a value still lower than the one of the present case (i. e., at Mach number 0.99, the cone-cylinder model would interfere even more with the mean flow).

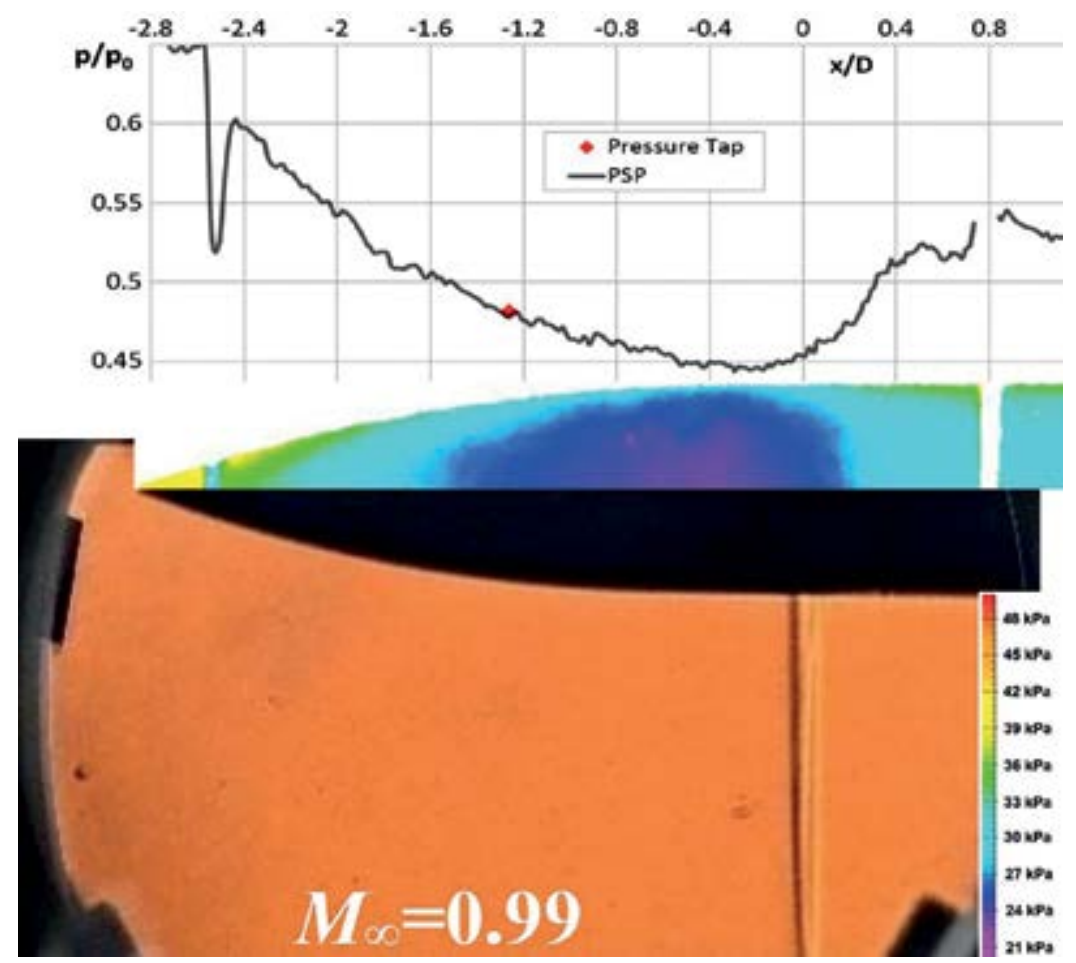

Figure 15. Comparison of results from PSP technique and Schlieren image for tangent-ogive model with a blockage area ratio of $0.78 \%$ for a stagnation pressure of $80 \mathrm{kPa}$ and a stagnation temperature of about $300 \mathrm{~K}$.

After the expansion, it is possible, looking carefully, to observe that the pressure returns to undisturbed condition in two steps. The first one, up to $x / D \approx 0.23$, corresponding to compression waves, and the second one from this point to $x / D \approx 0.35$, regarding to the shock wave occurrence. After this point, the pressure suffers some adaptation, probably due to the tri-dimensionality of the flow.

At $x / D=0.79$ position, there is a discontinuity in the curve that corresponds to the intermediate piece between the two parts of the body model, no longer painted with PSP paint, which was progressively removed because of the several changes in the model frontal configuration. There is no reason for such perturbation in the pressure curve after the shock wave, as it can be seen in Schlieren and PSP images, a reason for further investigation.

Figure 16 shows comparison between PSP technique and Schlieren image for tangent-hemispheric model with a blockage area ratio of $0.78 \%$, and for a Mach number of 0.99 . Unfortunately, there was no pressure tap measurement, although the preceding cases give confidence in PSP results. The transition strip was not included to avoid interference with shock wave formation in laminar boundary layer close to the model tip.

A sudden pressure drop occurred close to the tip, reaching a pressure ratio of 0.36 , which corresponds to a local Mach number of 1.31. The pressure drop line has a small disturbance, whose cause is difficult to address; moreover, the local model surface has a rather unfavorable inclination for PSP technique measurement using just one camera.

After the expansion, there is another disturbance, caused by a deficiency in the surface, due to a small discontinuity between the hemispherical geometry and the tangent arc connecting it to the cylindrical part. Along the length of this arc, the pressure suffers only small variations, corresponding to a Mach number variation between 1.25 and 1.31. In the region near the beginning of the cylindrical part of the body, the interface is smooth, resulting in an even pressure distribution, which indicates a region with very feeble expansion and compression waves. 


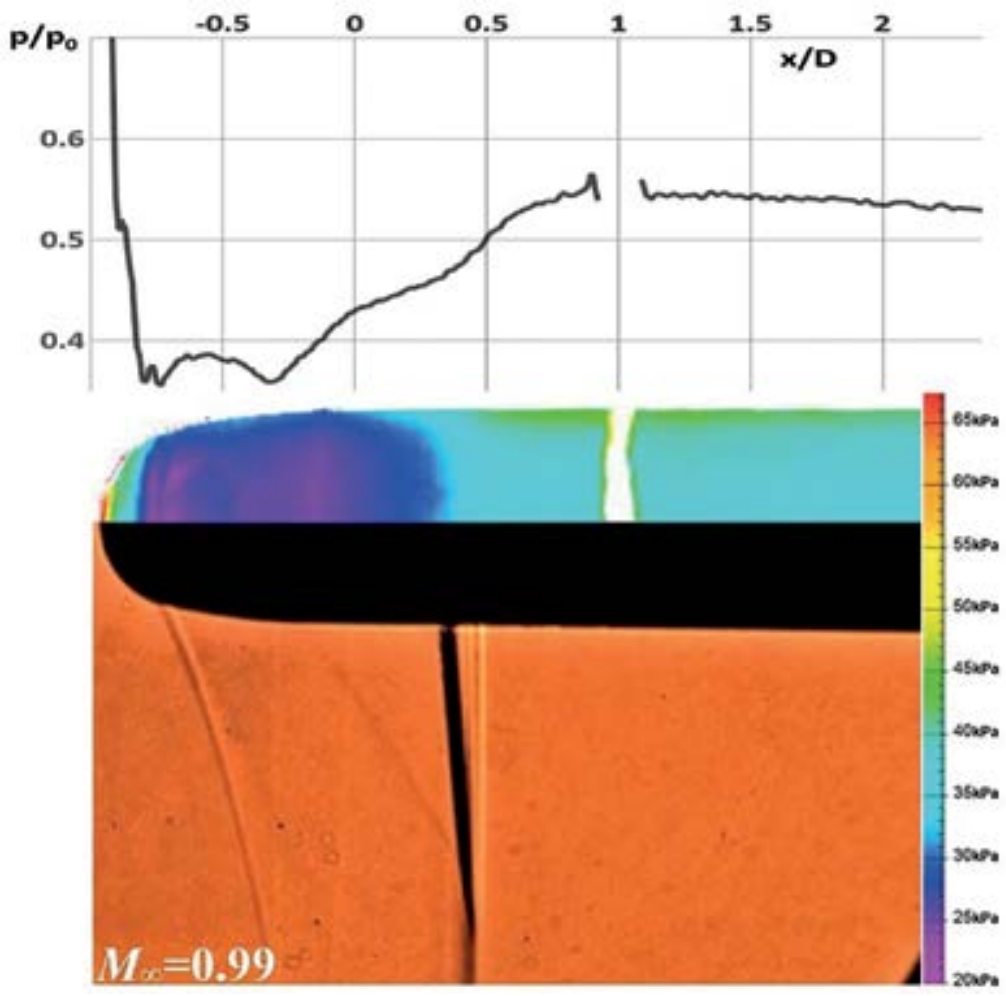

Figure 16. Comparison of results from PSP technique and Schlieren image for tangent-hemispheric model with a blockage area ratio of $0.78 \%$ for a stagnation pressure of $80 \mathrm{kPa}$ and a stagnation temperature of about $300 \mathrm{~K}$.

While the positioning of the shock wave in the Schlieren image is clearly observed at $x / D \approx 0.36$, in the pressure distribution graph it is more difficult to determine it, starting approximately at $x / D \approx 0.35$ and ending at $x / D \approx 0.57$.

After the shock wave, the pressure ratio is about 0.545 , corresponding to a local Mach number of 0.973 , which is just a little below the undisturbed Mach number. The pressure ratio still undergoes a continuous drop until reaching a value of 0.530 at the very end of the graph, corresponding to a local Mach number of 0.997.

A comparison of the pressure distribution with these three models can show interesting aspects that have to be considered by designers of transonic vehicles. The PSP pressure distribution results along the centerline of the models are plotted in a graphic in Fig. 17. In all cases, the origin of longitudinal axis is at the point where the geometry becomes cylindrical. It is notorious the differences among them.

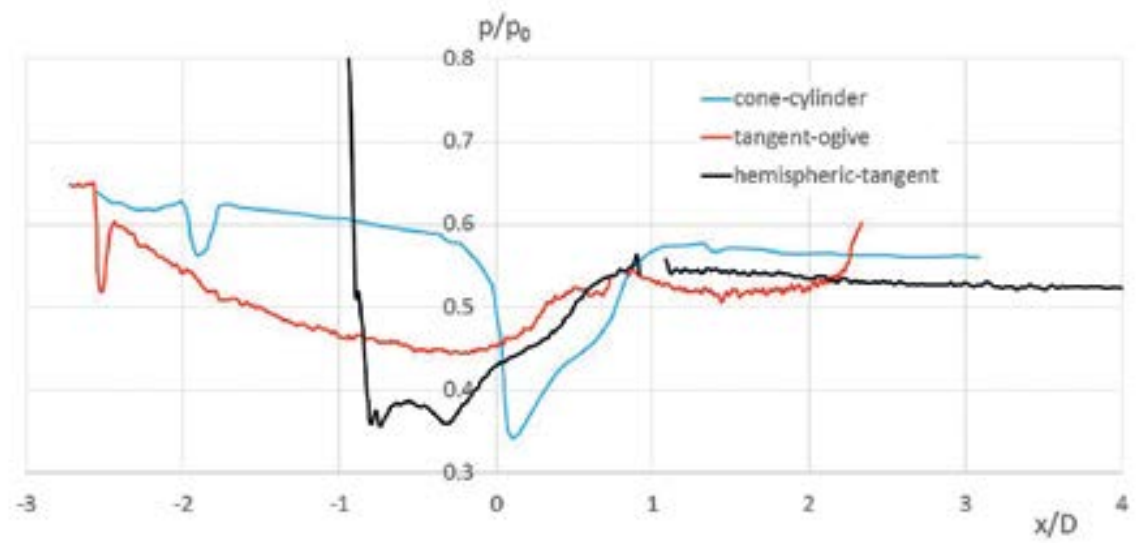

Figure 17. Comparison of pressure ratio for all three cases. Mach number of 0.95 for cone-cylinder, and 0.99 for tangent-ogive and tangent-hemispheric. 
The cone-cylinder has the least initial impact of all, but the strong expansion at the corner (at the origin) resulted in the strongest pressure drop, which is followed by a strong shock wave formation, even more considering that the undisturbed Mach number for the cone-cylinder model is inferior than the others.

The tangent-hemispheric has the greatest initial impact of all cases, obviously because of the bluntness of its tip, and the pressure drop was lower than for the cone-cylinder case, followed by a shock wave formation.

Both cone-cylinder and tangent-hemispheric models had similar pressure rise after the expansion, through compression and shock waves, with the same extension of about one diameter.

The tangent-ogive has the least impact of all, and the shock wave is considerably weaker than in the other cases.

\section{CONCLUSION}

The transonic aerodynamic regime in typical vehicle models, with five different frontal geometry configurations mounted in a cylindrical body and having the standard cone-cylinder shape as baseline, were studied using experimental techniques of PSP and Schlieren. The configurations studied were: cone-cylinder, Haak, tangent-hemispheric, and hemispheric.

The test campaign was carried out in IAE`s TTP, and Mach numbers were varied from subsonic to low supersonic. Detailed description of the phenomena on and around the surface of each model was presented and discussed, using some study cases.

Comparing the pressure distribution along a centerline of each model, it was observed that the tangent-hemispheric has the greatest initial impact of all cases, and the pressure drop was lower than the one of the cone-cylinder case, followed by a shock wave formation. The cone-cylinder and the tangent-hemispheric models had similar pressure rise after the expansion, through compression and shock waves, with the same extension of about one diameter. The tangent-ogive has the least impact of all, and the shock wave is considerably weaker than in the other cases.

Finally, the research indicates that cone-cylinder forebody presents small disturbance up to the corner, where strong expansion appears, followed by a strong shock wave. On blunt fronts, there is an abrupt initial increase in pressure, with the same characteristic formations of strong expansion, followed by strong shock wave. In aerodynamic fronts, the two things are very much smoothed, resulting in continuous pressure variation and gentle expansion formations and shocks.

\section{FUNDERS}

Coordenação de Aperfeiçoamento de Pessoal de Nível Superior

[http://doi.org/10.13039/501100002322]

Grant \#2915/2013

Conselho Nacional de Desenvolvimento Científico e Tecnológico

[http://doi.org/10.13039/501100003593]

Grant \# 402233/2013

Grant \# 308829/2015-8 - DT

\section{AUTHOR'S CONTRIBUTION}

Writing, Falcão Filho JB and Avelar AC; Wind Tunnel Measurements, Falcão Filho JB and Avelar AC; Data analysis, Falcão Filho JB; Data Processing, Mendonça LS; Wind Tunnel Experiments, Mendonça LS. 


\section{REFERENCES}

Avelar AC, Falcão Filho JBP, Francisco CPF, Romero PGM (2018) Analysis of the flow patterns on the forebody section of a sounding vehicle in the transonic regime. J Braz Soc Mech Sci Eng 40:130. doi: https://doi.org/10.1007/s40430-018-1030-y

Babinsky H, Harvey JK (2011) Shock wave-boundary-layer interactions. Cambridge: Cambridge University Press; [accessed 2017, May 10]. www.cambridge.org/9780521848527

Badri Narayanan MA, Ramjee $\mathrm{V}$ (1969) On the criteria for reverse transition in a two-dimensional boundary layer flow. $J$ Fluid Mech 35(2):225-241. doi: https://doi.org/10.1017/S002211206900108X

Chin SS (1961) Missile configuration design. New York, Toronto, London: McGraw-Hill Book Company.

Da Mata HO (2013) Procedimento experimental para análise aerodinâmica do veículo lançador de microsatélites VLM-1(Term paper). São José dos Campos: Instituto Tecnológico de Aeronáutica. In Portuguese.

Fanini Leite H, Avelar AC, Falcão Filho JBP (2017) Experimental study of shock wave formation patterns over an airfoil on laminar flow and its relationship with boundary layer transition. Paper present 33rd AIAA Aerodynamic Measurement Technology and Ground Testing Conference, Denver. doi: https://doi.org/10.2514/6.2017-3734

Falcão Filho JBP, Avelar AC, Reis MLCC (2009 January-June) Historical review and future perspectives for pilot transonic wind tunnel of IAE. J Aerosp Technol Manag 1(1):19-27. doi: https://doi.org/10.5028/jatm.2009.01011927

Falcão Filho JBP, Reis MLCC, Morgenstern Jr. A (2011) Experimental results from the sounding vehicle Sonda III test campaign in the pilot transonic wind tunnel. J Aerosp Technol Manag 3(3):311-324. doi: https://doi.org/10.5028/jatm.2011.03033111.

Launder BE (1964) Laminarization of the turbulent boundary layer by acceleration. J Appl Mech 31(4):707. doi: https://doi. org/10.1115/1.3629738

Liu T, Sullivan JP (2005) Pressure and temperature sensitive paints. In: Experimental fluid mechanics. Berlin: Springer-Verlag; [accessed 2017, July 06]. http://www.springer.com/978-3-540-22241-5. doi: https://doi.org/10.1002/9780470686652.eae076

Medeiros JG, Avelar AC, Falcão Filho JBP (2016) Experimental study of geometric variations effects on the flow patterns on a hammerhead satellite launch vehicle. Paper presented 30th Congress of the International Council of the Aeronautical Sciences, Daejeon, South Korea.

Merzkirch W (2007) Density-based techniques. In: Tropea C, Yarin AL, Foss JF. The springer handbook of experimental fluid mechanics Berlin: Springer-Verlag.

Moretti PH, Kays WM (1965) Heat transfer through an incompressible turbulent boundary layer with varying free-stream velocity and varying surface temperature. Int J Heat Mass Transf 8(9):1187-1202. doi: https://doi.org/10.1016/0017-9310(65)90062-1

Narashimha R, Sreenivasan KR (1973) Relaminarization in highly accelerated turbulent boundary layers. J Fluid Mech 61(3):417-447. doi: https://doi.org/10.1017/S0022112073000790

Nguyen TQT (2012) Numerical investigations of relaminarization in scramjet flows) (RWTH-CONV-112691) (PhD thesis). Aachen: Aachen University; [accessed 2017, June 05]. http://publications.nwth-aachen.de/record/50136/files/4072.pdf

Palmério AF (2016) Introdução à tecnologia de foguetes. São José dos Campos: Sindicato de Ciência e Tecnologia de São José dos Campos.

Patel VC, Head MR (1968) Reversion of turbulent to laminar flow. J Fluid Mech 34(2):371-392. doi: https://doi.org/10.1017/ S0022112068001953

Pope A, Goin KL (1978) High-speed wind tunnel testing. New York, London, Sydney: John Wiley \& Sons, Inc.

Ramaswamy MA, Rajendra G (1978) Experimental investigation of transonic flow past a blunt cone-cylinder. J Spacecr 15(2):120-123. doi: https://doi.org/10.2514/3.28001

Riper ABV (2004) Rockets and missiles. In: The life story of a tecnology. Westport: Greenwood Press.

Schraub FA, Kline SJ (1965) A study of the structure of the turbulent boundary layer with and without longitudinal pressure gradients. Stanford University Rep. MD-12.

Silva LM (2017) Aerodinâmica transônica de um veículo espacial com diferentes configurações frontais (MS Thesis) São José dos Campos: Instituto Tecnológico de Aeronáutica. In Portuguese.

Staff AR (1953) Equations, tables, and charts for compressible flow. NACA Rep. 1135. 